(C) 2020, The Authors. Published by Elsevier Inc. and Fass Inc. on behalf of the American Dairy Science Association ${ }^{\circledR}$. This is an open access article under the CC BY-NC-ND license (http://creativecommons.org/licenses/by-nc-nd/4.0/).

\title{
Validation of Brix refractometers and a hydrometer for measuring the quality of caprine colostrum
}

\author{
G. Zobel, ${ }^{1 *} \oplus$ R. Rodriguez-Sanchez, ${ }^{1} \odot$ S. Y. Hea, ${ }^{1} \oplus$ A. Weatherall, ${ }^{1} \oplus$ and R. Sargent ${ }^{2}$ \\ ${ }^{1}$ AgResearch Ltd., Ruakura Research Centre, 10 Bisley Road, Private Bag 3123, Hamilton 3214, New Zealand \\ ${ }^{2}$ Saskatoon Colostrum Company, Saskatoon, SK, Canada, S7K 6A2
}

\begin{abstract}
On-farm assessment of caprine colostrum quality is important for goat farmers; the ability to quickly recognize whether colostrum is suitable to feed to kids helps achieve successful passive transfer of immunity. The study compared the use of optical and digital Brix refractometers and a hydrometer against the international gold standard radial immunodiffusion (RID), using both fresh and frozen samples. A locally available ELISA methodology was included for comparison. A total of 300 samples were collected from 2 farms (farm $1: \mathrm{n}=157$, collected by research staff within $24 \mathrm{~h}$ of parturition; farm $2: \mathrm{n}=143$, collected by the farmer within $12 \mathrm{~h}$ of parturition). Farm 1 provided doe age for a subset of samples $(\mathrm{n}=86)$. Samples were tested fresh and then frozen for shipment and repeated testing. Specific gravity was measured using a hydrometer in a subset of samples $(n=22)$ from farm 2 . Because no gold standard thresholds are currently available for caprine colostrum, RID-derived values of 30,40 , and 50 g/L IgG were used as potential "good quality" thresholds. Pearson $(\rho)$ and Lin's concordance correlation coefficients (CCC) were calculated for comparison of methods. Optimum thresholds were established maximizing the Youden index and minimizing the "distance closest to the top left corner" of the receiver operator characteristic curves. Brix values were correlated with RID (optical Brix, fresh: $\rho=0.73$; digital Brix, fresh: $\rho=0.71$; digital Brix, frozen: $\rho=0.76)$ and with each other (range: $\rho=0.93$ to 0.99 ; $\mathrm{CCC}=0.91$ to 0.99 ). Specific gravity measured by the hydrometer yielded a strong relationship with RID $(\rho=0.83)$ and with Brix values (range: $\rho=0.88$ to 0.90 ). The ELISA method was not correlated with Brix methods (range: $\rho=0.02$ to 0.09$)$ or RID $(\rho=0.20)$. Depending on the colostrum IgG threshold, the hydrometer yielded high Youden indices (range: 0.78 to 0.93 ) and low distance closest
\end{abstract}

Received January 6, 2020.

Accepted June 8, 2020.

*Corresponding author: gosia.zobel@agresearch.co.nz to the top left corner criteria (0 to 0.05$)$ at a threshold of 1.047 specific gravity. For all RID IgG thresholds, the best Brix threshold (regardless of type or whether the sample was fresh or frozen) was 18 or $19 \%$, with the highest Youden indices (range: 0.47 to 0.61 ) and lowest distance to the top left corner criteria (range: 0.09 to 0.16 ); however, we recommend $19 \%$, because this reduces the potential of feeding poor-quality colostrum. The ELISA method was the poorest predictor of colostrum concentration. Age was not found to affect colostrum quality; however, the sample size of this subset was small. Hydrometers are inexpensive and easy to use, whereas Brix methods use only a small amount of colostrum; we suggest that either method could be used on-farm.

Key words: dairy goat, immunoglobulin G, failure of passive transfer, Saanen

\section{INTRODUCTION}

Early and adequate intake of high-quality colostrum after birth in newborns of semi-placental species, such as the goat, is essential for early immune status and good health before the animal's own immune system develops. The concentration of immunoglobulins in colostrum is an important factor in achieving an adequate passive transfer of immunity. This transfer is measured by serum immunoglobulin concentrations, with most work focusing on IgG. In calves, higher serum IgG concentrations reduce disease susceptibility (calves: Virtala et al., 1999; Weaver et al., 2000; lambs: Alves et al., 2015), and a range of successful passive transfer thresholds for serum IgG have been suggested for calves (e.g., 10 g/L, Besser et al., 1991; 12 g/L, Tyler et al., 1999; $15 \mathrm{~g} / \mathrm{L}$, Selim et al., 1995; $16 \mathrm{~g} / \mathrm{L}$, McGuire and Adams, 1982). The values available for small ruminants are less abundant. For lambs, both Hunter et al. (1977) and Alves et al. (2015) suggest $15 \mathrm{~g} / \mathrm{L}$, whereas for goat kids, there is a tendency to use $12 \mathrm{~g} / \mathrm{L}$. The latter stems from a suggestion by O'Brien and Sherman (1993) that higher morbidity and mortality occur below this threshold; however, that work used a small number 
of kids and relied on the group's mean $\operatorname{IgG}$ value to determine the cut-off. Adding to the scarcity of literature in goats is the lack of information about factors influencing serum $\operatorname{IgG}$ (e.g., optimum amount, timing, and quality of colostrum). The latter is particularly relevant to our study. For instance, in dairy cows, a frequently cited threshold for good-quality colostrum is $>50 \mathrm{~g} / \mathrm{L} \mathrm{IgG}$ (Kruse, 1970; Chigerwe et al., 2008). Indeed, to reach passive transfer of immunity, it is suggested that calves must consume a minimum of 150 $\mathrm{g}$ of IgG (Chigerwe et al., 2008), whereas in lambs a minimum value of $30 \mathrm{~g}$ of $\operatorname{IgG}$ is required (Alves et al., 2015); in goats, this information is lacking. Castro et al. (2005) allocated colostrum IgG by BW, and found that $3 \mathrm{~g} / \mathrm{kg}$ of BW (e.g., $10 \mathrm{~g}$ of IgG for an average newborn goat kid) resulted in most serum IgG values being $<10 \mathrm{~g} / \mathrm{L}$. Bentley (2018) suggested that kids should ingest at least $10 \%$ of their BW of colostrum within $24 \mathrm{~h}$ of birth, but unfortunately the author did not indicate the source of this value and did not report IgG concentration. Therefore, it is not yet possible to conclude the $\operatorname{IgG}$ concentration of good-quality caprine colostrum. To our knowledge, no robust evaluations of the link between different colostrum IgG concentrations and serum IgG have been conducted for goats; thus, a conclusive threshold for good-quality caprine colostrum does not exist.

Colostrum quality can be assessed through direct and indirect measures of IgG. The most accurate method is radial immunodiffusion (RID; Oyeniyi and Hunter, 1978; Chigerwe et al., 2008; Bartier et al., 2015), which is considered the laboratory gold standard for comparison with other methods. To minimize the number of plates needed, RID is performed in batches and therefore always uses frozen colostrum; however, there is no standardization for how colostrum is preserved when other methods are tested (fresh vs. frozen; Table 1). There is some evidence that neither refrigeration nor freezing reduces IgG concentrations and therefore both are suitable methods for storing caprine colostrum (Argüello et al., 2003); freezing does not appear to result in differences in serum IgG in calves (Holloway et al., 2001) or kids (Argüello et al., 2006). Regardless of sample handling, determining IgG content via RID must be performed in a laboratory by a trained individual, requires specialized knowledge and supplies, is expensive and requires time, and therefore it is impractical for on-farm application. Although ELISA tests do not correlate well with RID in dairy cows (Gelsinger et al., 2015), they have been used to assess colostrum quality in goats, sheep, and cows (Rudovsky et al., 2008; Romero et al., 2013; Alves et al., 2015; Gelsinger et al., 2015; Kessler et al., 2019). Unfortunately, these assays also do not have on-farm application. Like RID, ELISA testing is cost prohibitive and requires kits and expertise to be run correctly. Therefore, hydrometers and refractometers have served as simple, and readily available, indirect methods of colostrum IgG measurement, and both correlate well with RID for cow colostrum (Chigerwe et al., 2008; Bielmann et al., 2010; Quigley et al., 2013; Morrill et al., 2015; Bartens et al., 2016; Silva-del-Río et al., 2017). In goats, Caja et al. (2006) reported that specific gravity of colostrum, as measured by a hydrometer, correlates positively with RID. In ewes, Brix refractometers have been used to estimate colostrum quality (Torres-Rovira et al., 2017) but they have not been validated. A summary of validation studies is provided in Table 1.

Differences in goat colostrum quality have been reported. An average of $72.0 \mathrm{~g} / \mathrm{L}$ IgG was reported in Saanen goats (Yang et al., 2009). Those authors used RID, whereas studies using various goat IgG ELISA kits have reported lower mean values for other breeds (e.g., $28.2 \mathrm{~g} / \mathrm{L} \mathrm{IgG} \mathrm{in} \mathrm{Murciano-Granadina,} \mathrm{Romero} \mathrm{et}$ al., 2013; $41.2 \mathrm{~g} / \mathrm{L} \mathrm{IgG}$ in Majorera, Moreno-Indias et al., 2012; $49.1 \mathrm{~g} / \mathrm{L} \mathrm{IgG} \mathrm{in} \mathrm{Weiße} \mathrm{Deutsche} \mathrm{Edelziege,}$ Rudovsky et al., 2008). This variation in colostrum IgG concentration likely stems in part from the methodology used but it nonetheless demonstrates that evaluating colostrum quality before feeding it to kids is essential to achieve successful passive transfer of immunity.

To date, no work has assessed multiple on-farm methods to determine colostrum quality in goats and compare these results with the gold standard (RID) method. Therefore, the primary aim of the present study was to find an easy method by which farmers could assess colostrum quality on-farm, ensuring that their goat kids have the best start in terms of immune function. Three methods were compared: an optical Brix refractometer, a digital Brix refractometer, and a hydrometer, using RID as the reference method. An ELISA kit was also evaluated and compared with the gold standard method. To address an inquiry made by participating farmers, a secondary aim was included to assess the effect of doe age on colostrum quality.

\section{MATERIALS AND METHODS}

This study was undertaken in the Waikato region of New Zealand. All procedures involving animals were approved by the Ruakura Animal Ethics Committee under the New Zealand Animal Welfare Act 1999 (AE\# 14219).

\section{Animals}

Two commercial farms participated between July and August 2017. Farm 1 contributed 157 samples, and 
Zobel et al.: MEASURING CAPRINE COLOSTRUM QUALITY

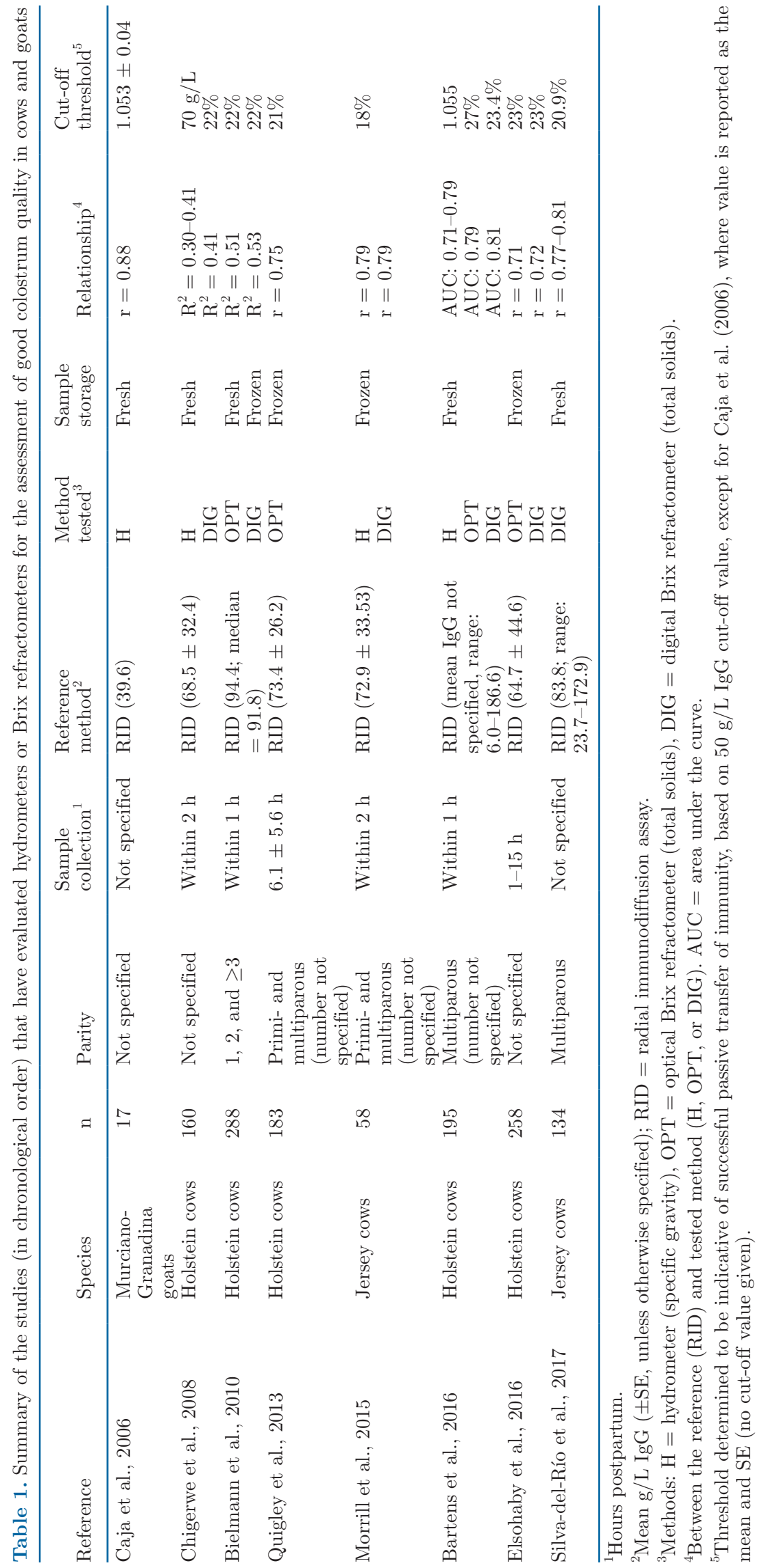


farm 2 contributed 143 samples, resulting in a total of 300 unique doe samples; all goats were Saanen or Saanen crosses. On farm 1, goats were all housed in large late-gestation group pens of approximately 400 animals. Does were typically marked by farm staff immediately after kidding, and kids could stay with the does until approximately $24 \mathrm{~h}$ postpartum. On farm 2 , does were housed in smaller late-gestation group pens of approximately 100 animals. Farm staff removed kids immediately after kidding, and freshly kidded does were milked according to each farm's typical milking procedure.

\section{Sample Collection and Handling}

On farm 1, over a 4-d period, a total of 157 does were sampled (median $=38$ does/d; range: $25-52$ does/d). All samples were collected between 1000 and $1530 \mathrm{~h}$, except those on $\mathrm{d} 2$, which were collected between 0830 and $1200 \mathrm{~h}$. Does were selected if they had been marked by farm staff, if they still had obvious signs of kidding (e.g., newborn kids near them, bloody discharge), or if research staff witnessed kidding. Does were carefully caught and restrained by straddling just behind the front legs. Using gloved (Thermo Fisher Scientific NZ Ltd., Auckland, New Zealand) hands, 3 strips of colostrum out of each teat were performed to break the keratin plug, if present. A separate teat disinfecting wipe (Mediwipes, Zoetis New Zealand Ltd., Auckland, New Zealand) was used to disinfect each teat end; the wipe was checked to ensure each teat end was clean before sample collection. The lid of the collection vial (50 $\mathrm{mL}$, Thermo Fisher Scientific NZ Ltd.) was unscrewed, and with the vial as close to horizontal as possible, colostrum was stripped into it, holding the teats at a $45^{\circ}$ angle to help prevent contamination. The vial was filled approximately halfway from one side of the udder and then filled from the other side of the udder. Care was taken to avoid contact between the vial and the teats. A disinfecting wipe was then used to clean off the teat ends. The goat was then marked on her head, using a livestock crayon, to prevent duplicate sampling.

On farm 2, over a 19-d period, a total of 143 goats were sampled. After parturition, does were put into the colostrum group and the farmer collected samples the first time the goat visited the milking parlor (e.g., samples were taken at both morning and afternoon milkings). The farmer was trained and followed the same procedure as described for farm 1 sample collection, with the following exceptions: (1) the goats were sampled in the milking parlor, and (2) the first 22 samples were collected into $300-\mathrm{mL}$ bottles (Thermo Fisher Scientific NZ Ltd.) to allow for specific gravity (hydrometer) testing. Samples were placed in the re- frigerator immediately after collection, and the research staff collected them once per day; therefore, the longest a sample would have been refrigerated before testing was $12 \mathrm{~h}$.

\section{Sample Analysis}

Analysis was done on fresh and frozen colostrum using the following methods: (1) digital Brix (fresh), (2) optical Brix (fresh), (3) specific gravity hydrometer (fresh), (4) ELISA (frozen), (5) digital Brix (frozen), and (6) RID (frozen). All samples were split into identical triplicate aliquots and then submitted for each analysis method, apart from the specific gravity hydrometer method, where only the 22 large $(300 \mathrm{~mL})$ fresh samples from farm 2 were tested. Frozen samples were held until the completion of the study and submitted together for analysis (e.g., frozen for approximately $30 \mathrm{~d})$.

The fresh samples were analyzed by research staff at Ruakura Research Centre (Hamilton, New Zealand) on the same day as collection from the farm. The digital Brix (fresh) (Starr Instruments, Victoria, Australia) and the optical Brix (fresh) (SHOOF International Ltd., Cambridge, New Zealand) were conducted using the manufacturers' provided instructions. The specific gravity hydrometer (SHOOF International Ltd.) required more colostrum $(300 \mathrm{~mL})$, so it was only possible for a subset of samples collected on farm 2. Manufacturer instructions were followed, which included ensuring that all samples were at approximately $20^{\circ} \mathrm{C}$; when one sample was at a higher temperature $\left(26^{\circ} \mathrm{C}\right)$, it was left on the benchtop for $1 \mathrm{~h}$, stirred, and tested after the temperature was confirmed to be approximately $20^{\circ} \mathrm{C}$. Specific gravity was recorded from the numerical scale on the device; however, if it was $<1.025$ or $>1.075$, only " $<1.025$ " or " $>1.075$ " was recorded. Each sample was tested 3 times and the values were averaged.

The frozen samples were sent for 3 additional analyses: (1) goat IgG ELISA; (2) digital Brix (frozen); and (3) RID, as follows. MilkTestNZ (Hamilton, New Zealand) performed a goat IgG ELISA (Quantitation Set E50-104; Bethyl Laboratories, Montgomery, TX) in triplicate, according to the protocol provided with the kit. For the digital Brix measurement, The Saskatoon Colostrum Company Ltd. (Saskatoon, SK, Canada) allowed samples to thaw at ambient temperature $\left(22^{\circ} \mathrm{C}\right)$. Because of the small volume of each sample, samples equilibrated to ambient temperature in just a few hours' time, at which point the digital Brix and the RID analyses were performed. The digital Brix analysis was performed following the manufacturer's instructions (Palm Abbe digital refractometer, model\# PA202x; Misco, Solon, OH). For the RID method, the 
samples were first diluted and then RID analysis of IgG concentration was conducted according to Bielmann et al. (2010), except that a commercially available goat serum was used to create the standard curve and obtain the regression line for calculating results. A reference goat serum (Triple J Farms, Bellingham, WA; cat. no. STN 228616) was used in each plate, at concentrations of $225,1,350$, and $2,700 \mathrm{mg} / \mathrm{dL}$, respectively, to create a 3-point standard curve. All samples were tested in duplicate on the same plate. Testing was repeated if the coefficient of variation of the duplicate results was $>10 \%$. Samples were also repeated using a different dilution if they were off the scale of the standard curve.

\section{Statistical Analysis}

The relationship between results of RID and those of other methods (digital Brix fresh, optical Brix fresh, digital Brix frozen, hydrometer, and ELISA) was explored by creating correlation plots and calculating Pearson correlation coefficients ( $\boldsymbol{\rho}$; Evans, 1996). Lin's concordance correlation coefficients (CCC) were calculated where relevant (e.g., comparing the Brix tests to one another, and comparing RID and ELISA, as these tests were measuring the same analyte); CCC is reported with $95 \%$ confidence intervals. Linear univariate models with RID as the dependent variable were used to calculate $\mathrm{R}^{2}$ values and generate trend lines. Where relevant, a $P$-value of $<0.05$ was used as an indicator of significance. The measures of test performance (sensitivity, specificity, and predictive values) were calculated using RID as the reference test; due to the lack of a confirmed threshold of "good quality" for caprine colostrum, 3 potential thresholds were used (30, 40, and $50 \mathrm{~g} / \mathrm{L} \mathrm{IgG)}$. The distance "closest to top left" corner of the receiver operator characteristic (ROC) curves was calculated for each test by taking the square root of the sum of 1 minus the sensitivity, squared, and 1 minus the specificity, squared (Perkins and Schisterman, 2006). The R package "pROC" (Xavier et al., 2011) was used to calculate test performance, Youden's index (Youden, 1950), and the distance to the top left corner of, and the area under, the ROC curve. The R package
"epiR" (Stevenson, 2020) was used to calculate Lin's CCC to measure test reproducibility (Lin, 1989). The effect of goat age on the concentration of colostrum IgG as determined by RID was investigated using ANOVA; this analysis was performed on a subset of animals from farm 1 for which birth year was available (86 out of 157 does enrolled). All statistical analysis and data manipulations were performed using the $\mathrm{R}$ software program (https://www.R-project.org/).

\section{RESULTS}

Descriptive statistics for all methods tested are presented in Table 2. Except for ELISA, strong correlations were present between all methods used and RID $(\rho>0.7$; Table 3$)$. The ELISA results were only very weakly correlated with the other methods (range: $\rho=0.02$ to 0.05 for Brix methods; 0.20 for RID). Lin's CCC results were consistent with Pearson correlations, with Brix values being strongly reproducible with one another $(\mathrm{CCC}=0.93-0.98)$ and no reproducibility existing between ELISA and RID (Table 4). The hydrometer (fresh) method had the highest $R^{2}$ (0.69; Figure 1a), Brix methods were intermediate (Figure 1b), and ELISA had the lowest $\mathrm{R}^{2}$ (0.04; Figure 1c).

Diagnostic test performance for Brix (Table 5) and hydrometer and ELISA (Table 6) are reported for 3 potential "good-quality colostrum" thresholds of 30, 40, and $50 \mathrm{~g} / \mathrm{L}$ IgG. Figure 2 presents ROC curve comparisons for the same thresholds. The areas under the curve (AUC) for the Brix readings were similar and were 0.86 (30 g/L IgG threshold), from 0.82 to 0.84 (40 g/L IgG threshold), and from 0.83 to $0.86(50 \mathrm{~g} / \mathrm{L}$ IgG threshold). The Brix methods, regardless of the RID IgG threshold used, had the highest Youden indices (ranging from 0.47 to 0.61 ) of all methods and the lowest distance to the top left corner criteria (ranging from 0.09 to 0.16 ) at either 18 or $19 \%$. The hydrometer had the highest AUC of all methods, ranging from 0.88 for the lowest IgG threshold to 0.99 for the 40 and 50 $\mathrm{g} / \mathrm{L}$ IgG thresholds. The hydrometer's optimum specific gravity threshold of 1.047 yielded Youden indices ranging from 0.78 (30 g/L IgG threshold) to 0.93 for

$\begin{aligned} & \text { Table 2. Descriptive statistics for the estimation of IgG concentrations in fresh and frozen colostrum sampled } \\
& \text { from } 2 \text { farms, as established using digital or optical Brix refractometers, a hydrometer, an ELISA and RID }\end{aligned}$
\begin{tabular}{lcccccc} 
Method & n & Mean & Maximum & Minimum & Median & SD \\
\hline Digital Brix (fresh) (\%) & 300 & 20.0 & 36.6 & 9.5 & 19.9 & 4.3 \\
Optical Brix (fresh) (\%) & 300 & 20.0 & 32.0 & 10.4 & 19.8 & 4.2 \\
Hydrometer (fresh) (specific gravity) & 22 & 1.049 & 1.064 & 1.026 & 1.05 & 0.009 \\
Digital Brix (frozen) (\%) & 300 & 19.4 & 36.6 & 8.3 & 19.1 & 4.2 \\
ELISA (g/L) & 298 & 20.7 & 72.5 & 1.6 & 20.1 & 11.3 \\
RID (g/L) & 300 & 63.4 & 186.1 & 1.8 & 58.2 & 35.4 \\
\hline
\end{tabular}

${ }^{1}$ Radial immunodiffusion assay, gold standard. 
Table 3. Pairwise Pearson correlation coefficients $(\rho)$ between the digital and optical Brix refractometers, ELISA, hydrometer, and RID for the detection of colostrum IgG in fresh and frozen caprine colostrum collected from 2 farms

\begin{tabular}{lccccc}
\hline Method & $\begin{array}{c}\text { Optical Brix } \\
\text { (fresh) }\end{array}$ & $\begin{array}{c}\text { Digital Brix } \\
\text { (fresh) }\end{array}$ & ELISA & $\begin{array}{c}\text { Digital Brix } \\
\text { (frozen) }\end{array}$ & $\begin{array}{c}\text { RID } \\
\operatorname{IgG}^{1}\end{array}$ \\
\hline Hydrometer (fresh) & 0.88 & 0.88 & 0.05 & 0.90 & 0.83 \\
Optical Brix (fresh) & & 0.99 & 0.02 & 0.94 & 0.73 \\
Digital Brix (fresh) & & 0.03 & 0.94 & 0.71 \\
ELISA $^{2}$ & & & 0.09 & 0.20 \\
Digital Brix (frozen) & & & & 0.76 \\
\hline
\end{tabular}

${ }^{1}$ Radial immunodiffusion assay, gold standard.

${ }^{2}$ No relationships with ELISA were significant; all other relationships were significant at $P<0.0001$.

the other IgG thresholds. This optimum threshold also resulted in a distance to the top left corner criteria ranging from 0 to 0.05 . The ELISA had the lowest AUC values, ranging from 0.56 (30 g/L IgG threshold) to $0.59(50 \mathrm{~g} / \mathrm{L} \mathrm{IgG}$ threshold); even at the optimum threshold of $14 \mathrm{~g} / \mathrm{L}$, the Youden index ranged from 0.15 to 0.17 and the distance to the top left corner criteria ranged from 0.39 to 0.41 . For all methods (Table 5 and Table 6), increasing the test thresholds while holding RID IgG constant resulted in an increase in specificity (and positive predictive value), with a corresponding decrease in sensitivity. For each test threshold, increasing RID IgG thresholds from 30 to $50 \mathrm{~g} / \mathrm{L}$ increased test sensitivity and decreased test specificity.

For the subset of samples for which doe age was available, the ages ranged from 1 to $5 \mathrm{yr}$; the group mean RID of these samples was $59.6 \mathrm{~g} / \mathrm{L} \mathrm{IgG} \mathrm{(range:}$ 4.4 to 170.7). There was no difference in colostrum IgG concentration between the age groups $(P>0.9$; Figure $3)$.

\section{DISCUSSION}

The caprine colostrum IgG concentration measured by the reference method (RID) in this study (63.4 \pm $35.4 \mathrm{~g} / \mathrm{L}$; mean $\pm \mathrm{SD}$ ) is similar to, albeit more variable than, the concentration reported in the literature using the same method in Saanen goat colostrum (72.0 $\pm 4.13 \mathrm{~g} / \mathrm{L}$; Yang et al., 2009). Yang et al. (2009) collected the colostrum samples at a specific time post-

Table 4. Pairwise Lin's concordance correlation coefficients (CCC) between the digital and optical Brix refractometers, and between ELISA and RID for the detection of colostrum IgG in fresh and frozen caprine colostrum collected from 2 farms

\begin{tabular}{lcc}
\hline Item & CCC & $95 \%$ CI \\
\hline Digital Brix (fresh) vs. optical Brix (fresh) & 0.99 & $0.98-0.99$ \\
Digital Brix (fresh) vs. digital Brix (frozen) & 0.93 & $0.91-0.94$ \\
Optical Brix (fresh) vs. digital Brix (frozen) & 0.93 & $0.91-0.94$ \\
ELISA vs. RID $^{1}$ & 0.05 & $0.02-0.08$ \\
\hline
\end{tabular}

${ }^{1}$ Radial immunodiffusion assay, gold standard. partum, which likely contributed to the lower variation reported compared with our results.

When using the hydrometer, the specific gravity of the colostrum $(1.049 \pm 0.009)$ in our study was similar to that previously reported $(1.053 \pm 0.002$, Caja et al., 2006; $1.0443 \pm 0.0073$, Rudovsky et al., 2008); although no cut-off has been suggested for goats, our cut-off threshold (1.047) was lower than that reported for cows (1.054 to 1.055; Bartens et al., 2016). Specific gravity correlated highly with RID, in accordance with Argüello et al. (2006) and Caja et al. (2006), who reported correlations of 0.69 and 0.88 , respectively. The test performance of the specific gravity hydrometer was highest of all methods in the current study. Although the results were based on a small sample size of 22 animals, we suggest that the hydrometer is a promising and practical method for estimating the quality of caprine colostrum. The performance of the specific gravity test would benefit from further study using a larger sample size. Most devices comprise just 2 components and include an easy-to-read, color-coded floating unit, making them a simple and cost-effective option. Nonetheless, hydrometers do have some disadvantages. First, they require more colostrum (the unit we tested required $300 \mathrm{~mL}$ ) and the testing container must be cleaned well before reuse to reduce the potential of pathogen contamination between batches. Second, hydrometers are sensitive to temperature. We ensured that testing was completed at approximately $20^{\circ} \mathrm{C}$; however, on-farm, this is not always practical. As such, Brix refractometers (digital and optical) should be preferentially considered because they perform well at any temperature (Bielmann et al., 2008).

Both optical and digital Brix refractometers measure and operate in a similar way, measuring the refractive index of a liquid (Bielmann et al., 2010). For the goat colostrum in this study, optical and digital Brix refractometers yielded similar results and were strongly correlated with the gold standard method (RID) for estimation of IgG concentration. Digital Brix values for fresh and frozen samples were strongly correlated and 

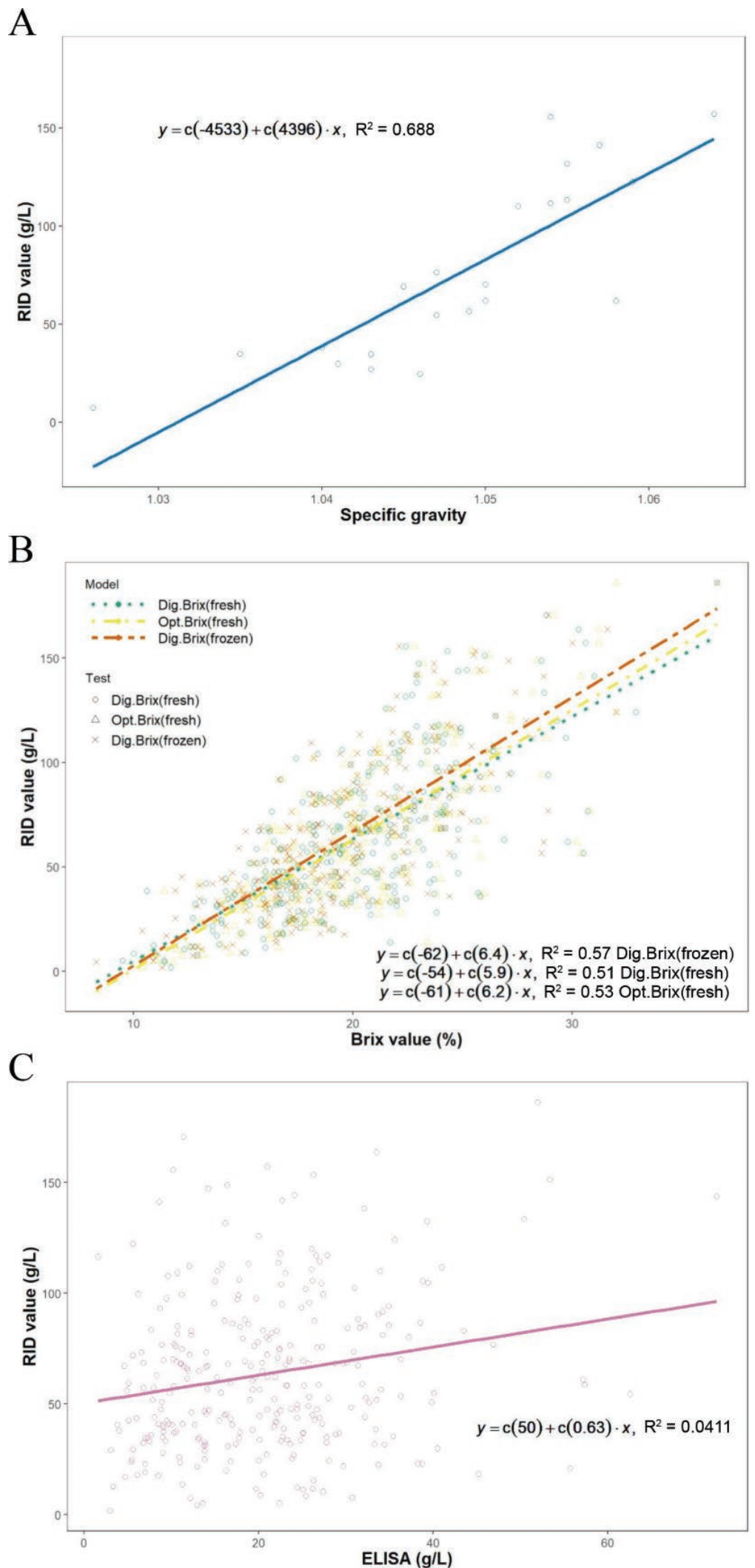

Figure 1. Correlation plots, $\mathrm{R}^{2}$ values, and trend lines are presented for all methods evaluated: (A) hydrometer $(\mathrm{n}=22)$; $(\mathrm{B})$ digital (Dig.) Brix (fresh), optical (Opt.) Brix (fresh), and digital Brix (frozen) $(\mathrm{n}=300)$; and $(\mathrm{C})$ ELISA (frozen) $(\mathrm{n}=298)$. Radial immunodiffusion assay (RID) is the dependent variable. 


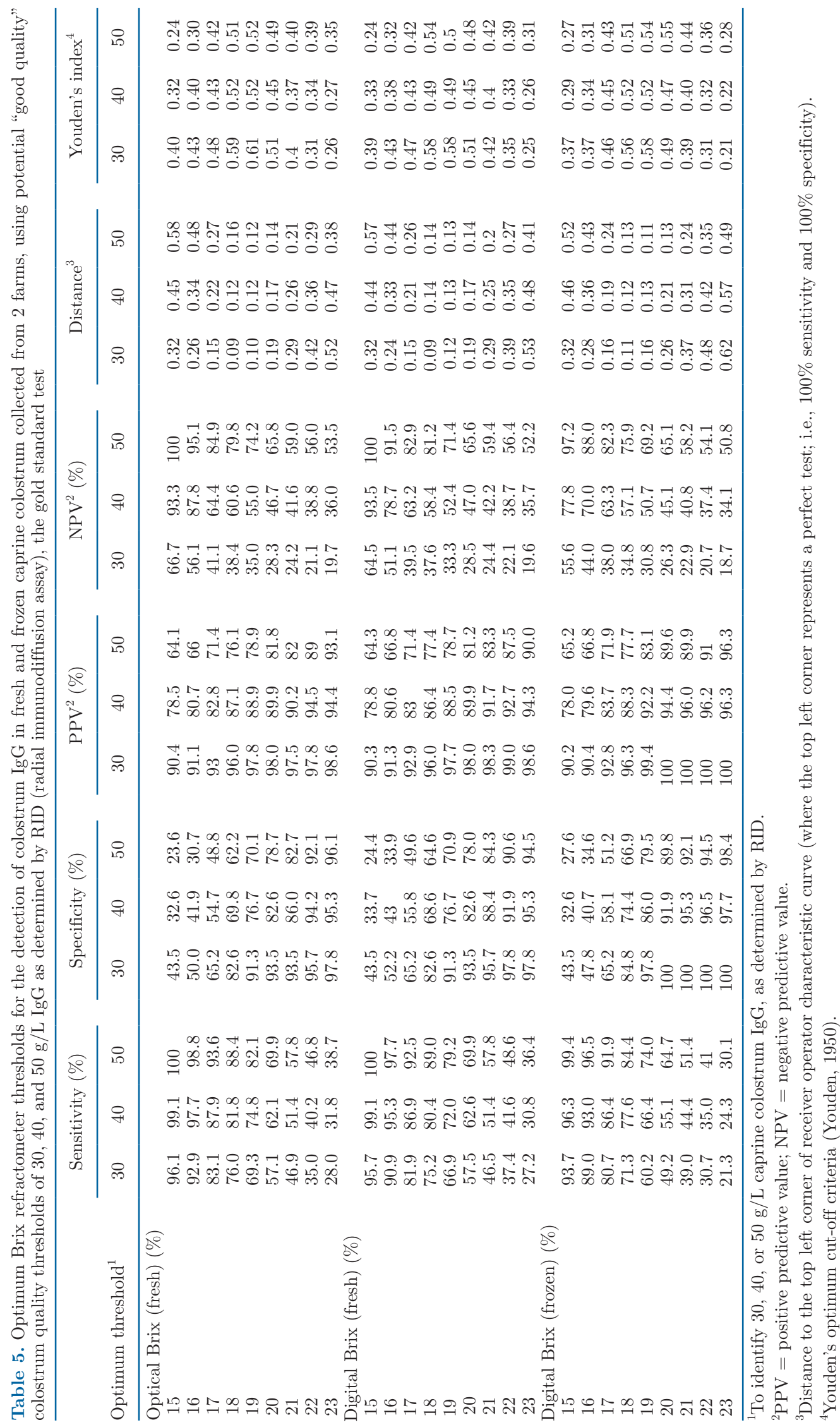


Zobel et al.: MEASURING CAPRINE COLOSTRUM QUALITY

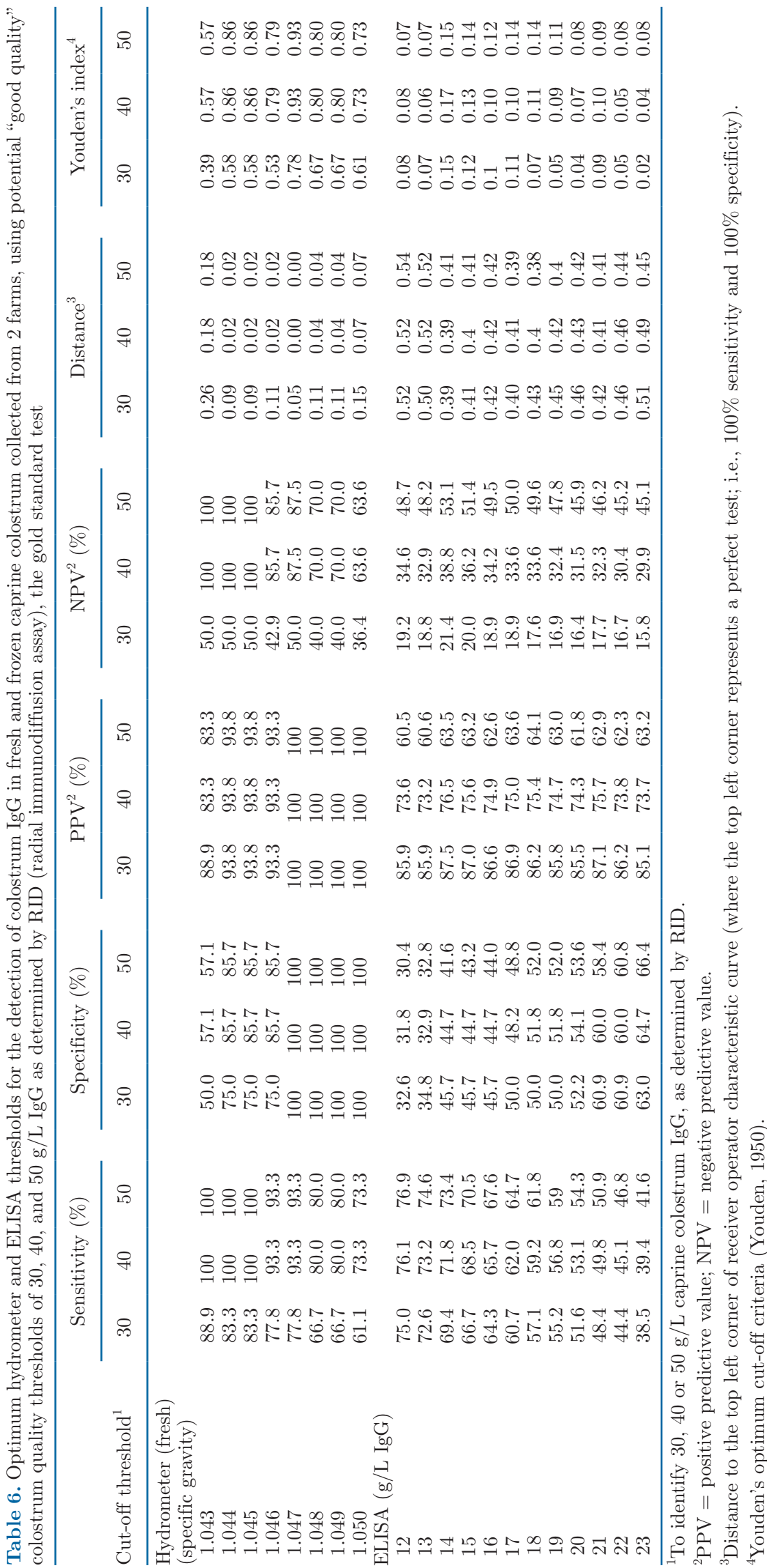


A

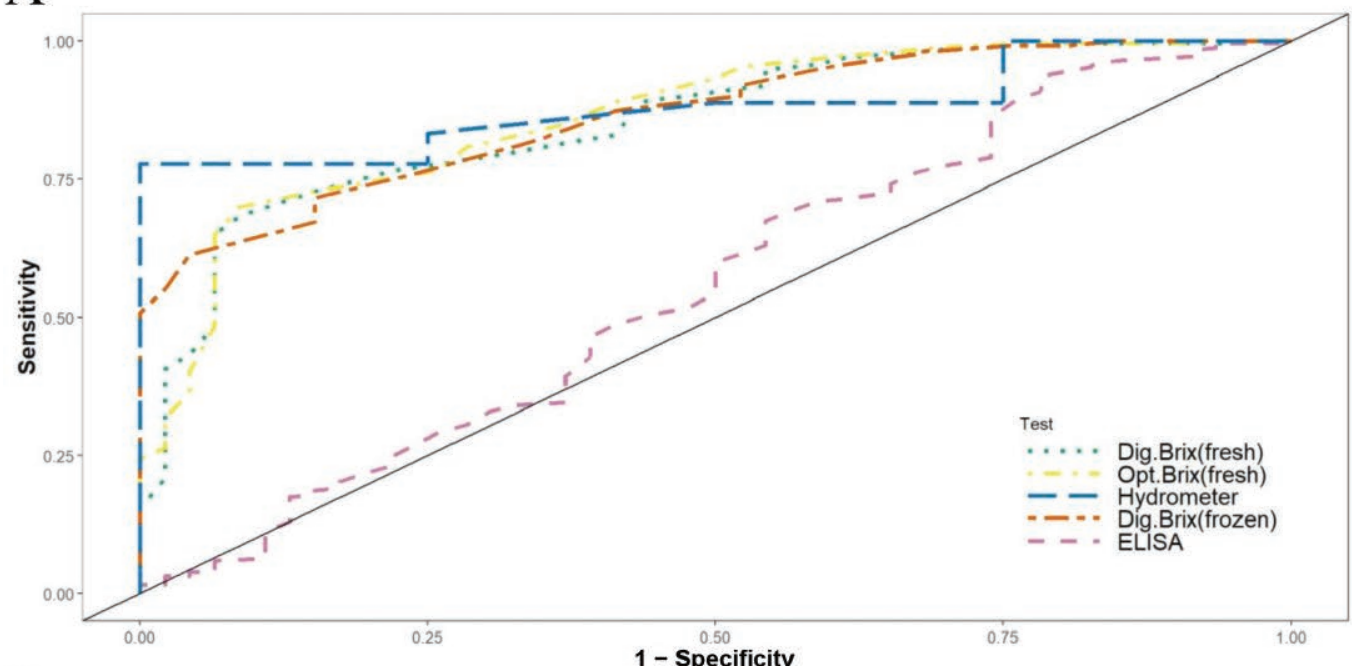

$\mathrm{B}$

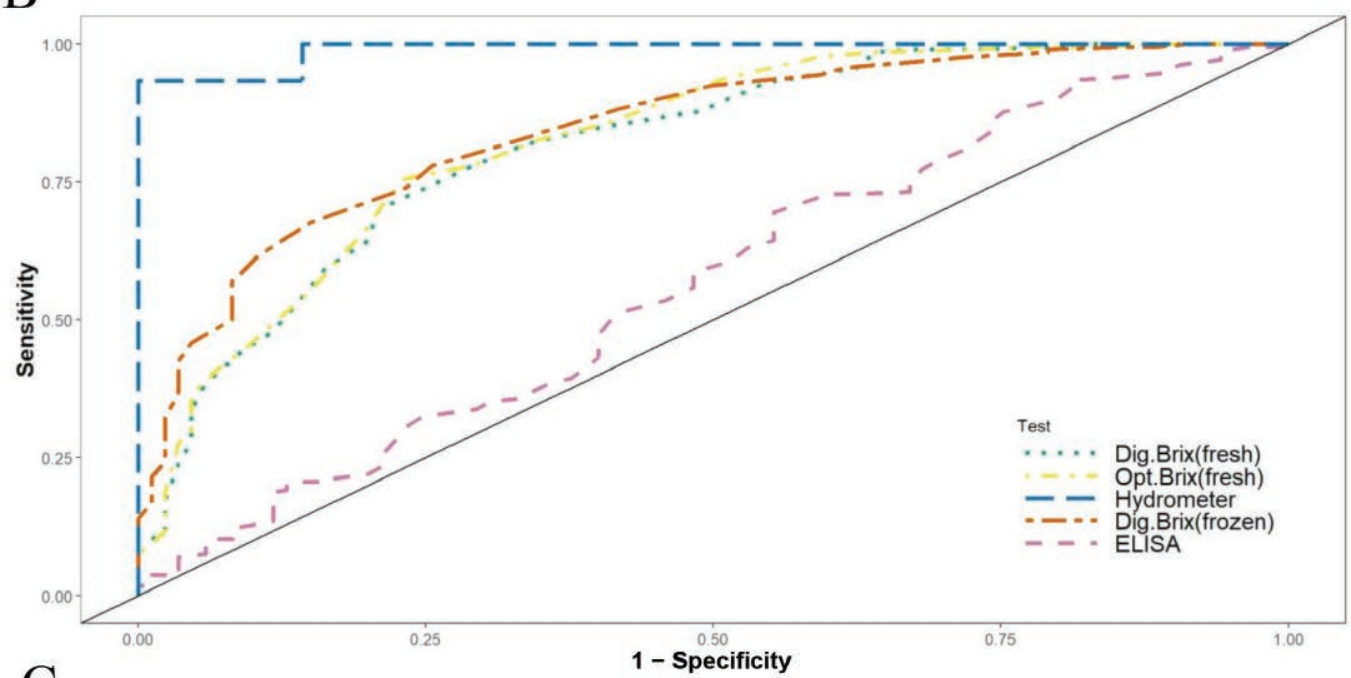

$\mathrm{C}$

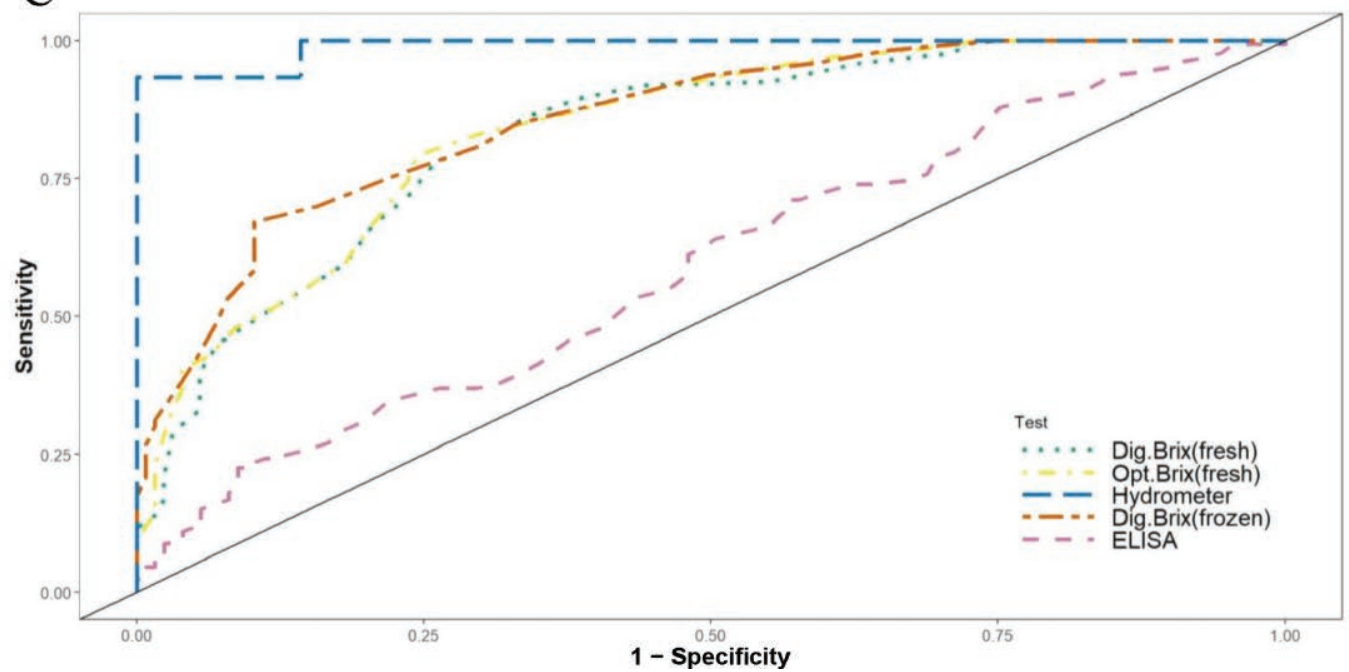

Figure 2. Receiver operator curve (ROC) comparison of test performance between the digital (Dig.) and optical (Opt.) Brix refractometers, ELISA, and hydrometer for the detection of caprine colostrum IgG, using a potential good-quality colostrum cut-off of (A) $30 \mathrm{~g} / \mathrm{L}$, (B) $40 \mathrm{~g} / \mathrm{L}$, and (C) $50 \mathrm{~g} / \mathrm{L} \mathrm{IgG}$, as determined by radial immunodiffusion assay (RID; gold standard test). 
highly reproducible. This aligns with previous work that determined that freezing and thawing samples did not alter the reading of Brix hydrometers (bovine: Bielmann et al., 2010; caprine: Argüello et al., 2003). The Brix refractometers were also strongly correlated with specific gravity. The use of Brix refractometers in small ruminants has not been widely studied. Torres-Rovira et al. (2017) evaluated the use of a digital Brix refractometer for the estimation of colostrum IgG concentration in ewes, reporting that it was a useful method for assessing colostrum quality; however, an ELISA was used as the reference method in that study. Despite this limitation, Torres-Rovira et al. (2017) suggested a similar Brix cut-off threshold value to that determined here. In our study, 18 and $19 \%$ cut-off thresholds were similar for the optical Brix (fresh), digital Brix (fresh), and digital Brix (frozen) methods in terms of both Youden indices and the distance to the closest top left corner optimal cut-off criteria; however, because the on-farm aim is to select good-quality colostrum, we suggest the cut-off value of $19 \%$ is more appropriate, as it resulted in increased specificity and positive predictive value, thus minimizing the potential of feeding poor-quality colostrum to kids.

The mean IgG concentration determined by ELISA $(20.7 \pm 11.3 \mathrm{~g} / \mathrm{L})$ was similar to the concentration reported with the same method in Murciano-Granadina goat colostrum $(28.23 \mathrm{~g} / \mathrm{L}, \mathrm{SEM}=1.308$; Romero et al., 2013); those authors did not interpret whether their ELISA-derived values were indicative of good- versus poor-quality colostrum. Castro et al. (2018) used an ELISA-based IgG value of $<20 \mathrm{~g} / \mathrm{L}$ to indicate poorquality colostrum; however, they did not indicate the source of this value, nor were their results presented in

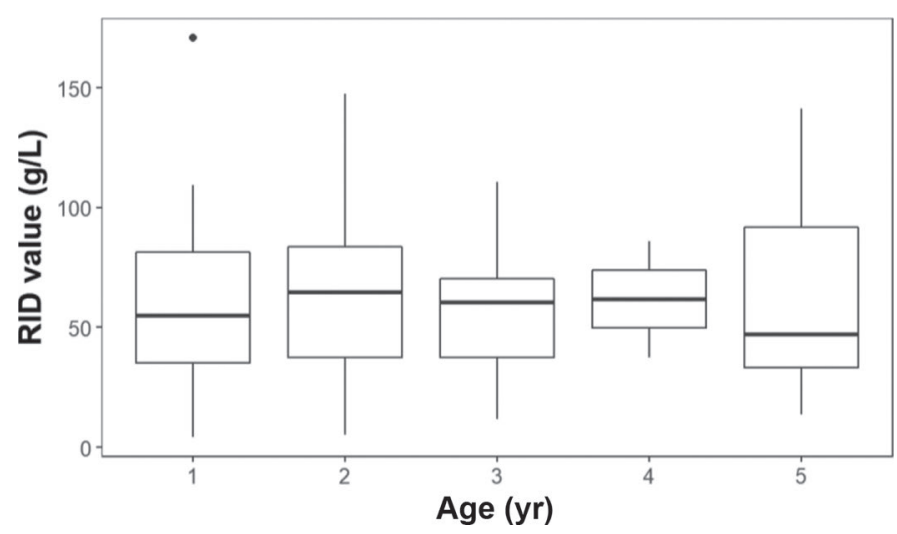

Figure 3. Colostrum IgG as determined by radial immunodiffusion assay (RID) for subset of goats from farm $1(\mathrm{n}=86)$, stratified by age ( 1 yr: $\mathrm{n}=34 ; 2$ yr: $\mathrm{n}=8 ; 3$ yr: $\mathrm{n}=12 ; 4$ yr: $\mathrm{n}=2 ; 5$ yr: $\mathrm{n}=30$ ). The thick horizontal lines indicate the median; box ends are the first and third quartiles. The ends of the vertical lines represent the minimum and maximum. Outliers are signified by a dot. a manner that allowed comparison with our work. The ELISA used in our study yielded low test performance measures and was weakly correlated and not reproducible with the gold standard RID test; this has been reported with cows as well (Gelsinger et al., 2015; Dunn et al., 2018). Therefore, we do not recommend the direct comparison of caprine colostrum IgG concentration values between studies that use different methods (e.g., ELISA versus RID).

There is a common belief among farmers that colostrum from young does has lower IgG concentration than colostrum from older does, resulting in colostrum being discarded. In our study, age of the goat did not affect colostrum IgG concentration; however, using the colostrum IgG values reported by Romero et al. (2013), we suggest that both studies (ours and theirs) were significantly underpowered to find parity differences in caprine colostrum IgG. Similarly, Argüello et al. (2006) reported no effect of lactation number, but they also used a small number of goats. We suggest that future work to evaluate the effect of parity on caprine colostrum needs a minimum group size of at least 393 animals (assuming an effect size of $0.20, \alpha=0.05,1$ $-\beta=0.80)$. Work in cows supports the idea that age increases colostrum quality. For instance, Oyeniyi and Hunter (1978) and Silva-del-Río et al. (2017) reported that cows in fourth or higher lactation had higher colostrum IgG than younger cows. Gulliksen et al. (2008) and Bielmann et al. (2010) also concluded that parity influences $\operatorname{IgG}$ concentration of colostrum in dairy cattle, but Gulliksen et al. (2008) found that cows in second parity produced colostrum of lesser quality than either first-parity cows or older cows, without suggesting potential contributing factors. Interestingly, others have found no effect of parity on colostrum quality (cows: Reschke et al., 2017; sheep: Torres-Rovira et al., 2017). The contradictory findings in these studies could be due to differences in the reference method used (e.g., RID, ELISA, or electrophoresis), the breed of the animals, or, as in the goat literature, animal numbers (i.e., the sample sizes ranged from 43 to 1,250).

A few factors were beyond the research team's control, and therefore should be considered when interpreting these results. First, because no threshold for "goodquality" colostrum has been established for goats, we opted for 3 potential thresholds: that used for cows (50 $\mathrm{g} / \mathrm{L} \mathrm{IgG)}$ and 2 lower thresholds. We caution that there is a need to confirm the efficacy of caprine colostrum with any of these values to achieve passive transfer of immunity (e.g., match various colostrum IgG concentrations with serum testing of kids, as has been done for cows; Kruse, 1970; Chigerwe et al., 2008). Second, because of the on-farm nature of the data collection, the research team had no control over the timing of 
colostrum collection. We found a large range in RIDdetermined colostrum IgG; this variability reflects that some goats contributed fresh colostrum immediately postpartum, whereas others may have already been suckled by their kids (farm 1) or may have had several hours pass between kidding and first milking (farm 2). Therefore, the range reported should not be used as an indicator of the typical on-farm colostrum quality range. Most research on colostrum quality testing (regardless of species) used minimal sources (e.g., 2 farms, Bielmann et al., 2010; 1 farm, Romero et al., 2013; 1 farm, Torres-Rovira et al., 2017); therefore, we suggest that future work include more farms to develop a better understanding of typical range in caprine colostrum quality. Third, because of availability of laboratory testing options, we were unable to complete the RID method on fresh colostrum or the optical Brix method on frozen colostrum. Although no detrimental effects of freezing have been demonstrated in previous work (Argüello et al., 2003) and the positive relationship between the other methods using fresh and frozen samples in our study suggest the RID results would be similar, we recommend follow-up work to confirm this.

\section{CONCLUSIONS}

The present study provides evidence of the usefulness of hydrometers and optical and digital Brix refractometers as on-farm methods for the assessment of caprine colostrum quality. Caprine colostrum yields lower values than bovine colostrum on refractometer devices; therefore, a cut-off threshold of $19 \%$ should be used to exclude lower quality colostrum. We suggest that the ability of refractometers to test small amounts of colostrum warrants using these options, particularly if the farmer's goal is to exclude low-quality colostrum. This is the first step in the improvement of the assessment of caprine colostrum quality at the farm level. The cut-off thresholds reported for these methods are estimations; the methods correlated well with the gold standard method (RID), but further studies are needed to fully qualify them because the threshold for good colostrum in goats has not yet been established, as it has for bovine colostrum. Although test availability prevented comparisons between fresh and frozen samples for all methods, the results suggest that freezing does not affect IgG content. We caution cross-study comparisons of caprine colostrum quality, especially if ELISA methods are used.

\section{ACKNOWLEDGMENTS}

The authors are grateful to both Dairy Goat Cooperative farmers for participating in the study; their dedication to accurate sample collection and labeling, as well as general record keeping, was instrumental to its successful completion. We also gratefully acknowledge AgResearch, Ruakura Research Centre (Hamilton, New Zealand) technicians, particularly Stephanie Delany and Remi Mathieu for their goat handling and sample collecting abilities. Funding for the study was provided by the New Zealand Ministry of Business, Innovation and Employment (Wellington, New Zealand; C10X1307) and the Dairy Goat Co-Operative (NZ) Ltd. (Hamilton, New Zealand). The authors have not stated any conflicts of interest.

\section{REFERENCES}

Alves, A. C., N. G. Alves, I. J. Ascari, F. B. Junqueira, A. S. Coutinho, R. R. Lima, J. R. O. Perez, S. O. De Paula, I. F. FurushoGarcia, and L. R. Abreu. 2015. Colostrum composition of Santa Inês sheep and passive transfer of immunity to lambs. J. Dairy Sci. 98:3706-3716. https://doi.org/10.3168/jds.2014-7992.

Argüello, A., N. Castro, S. Álvarez, and J. Capote. 2006. Effects of the number of lactations and litter size on chemical composition and physical characteristics of goat colostrum. Small Rumin. Res. 64:53-59. https://doi.org/10.1016/j.smallrumres.2005.03.016.

Argüello, A., N. Castro, J. Capote, R. Ginés, F. Acosta, and J. L. López. 2003. Effects of refrigeration, freezing-thawing and pasteurization on IgG goat colostrum preservation. Small Rumin. Res. 48:135-139. https://doi.org/10.1016/S0921-4488(02)00277-8.

Bartens, M. C., M. Drillich, K. Rychli, M. Iwersen, T. Arnholdt, L. Meyer, and D. Klein-Jöbstl. 2016. Assessment of different methods to estimate bovine colostrum quality on farm. N. Z. Vet. J. 64:263-267. https://doi.org/10.1080/00480169.2016.1184109.

Bartier, A. L., M. C. Windeyer, and L. Doepel. 2015. Evaluation of on-farm tools for colostrum quality measurement. J. Dairy Sci. 98:1878-1884. https://doi.org/10.3168/jds.2014-8415.

Bentley, J. 2018. Colostrum management for the dairy goat kid. Fact sheet. Iowa State University, Ames. Accessed Aug. 9, 2018. https: //www.extension.iastate.edu/dairyteam/people/jennifer-bentley.

Besser, T. E., C. C. Gay, and L. Pritchett. 1991. Comparison of three methods of feeding colostrum to dairy calves. J. Am. Vet. Med. Assoc. 198:419-422.

Bielmann, V., J. Garner, C. Throop, N. Perkins, and K. Leslie. 2008 An evaluation of a Brix refractometer for measurement of colostrum quality and success of passive transfer. J. Dairy Sci. 91(ESuppl. 1):354. (Abstr.)

Bielmann, V.. J. Gillan, N. R. Perkins, A. L. Skidmore, S. Godden, and K. E. Leslie. 2010. An evaluation of Brix refractometry instruments for measurement of colostrum quality in dairy cattle. J. Dairy Sci. 93:3713-3721. https://doi.org/10.3168/jds.2009-2943.

Caja, G., A. A. K. Salama, and X. Such. 2006. Omitting the dry-off period negatively affects colostrum and milk yield in dairy goats. J. Dairy Sci. 89:4220-4228. https://doi.org/10.3168/jds.S0022 $-0302(06) 72467-5$.

Castro, N., J. Capote, S. Álvarez, and A. Argüello. 2005. Effects of lyophilized colostrum and different colostrum feeding regimens on passive transfer of immunoglobulin $\mathrm{G}$ in Majorera goat kids. J. Dairy Sci. 88:3650-3654. https://doi.org/10.3168/jds.S0022 -0302(05)73050-2.

Castro, N., L. A. Gómez-González, B. Earley, and A. Argüello. 2018. Use of clinic refractometer at farm as a tool to estimate the $\mathrm{IgG}$ content in goat colostrum. J. Appl. Anim. Res. 46:1505-1508. https://doi.org/10.1080/09712119.2018.1546585.

Chigerwe, M., J. W. Tyler, J. R. Middleton, J. N. Spain, J. S. Dill, and B. J. Steevens. 2008. Comparison of four methods to assess colostral IgG concentration in dairy cows. J. Am. Vet. Med. Assoc. 233:761-766. https://doi.org/10.2460/javma.233.5.761. 
Dunn, A., C. Duffy, A. Gordon, S. Morrison, A. Argúello, M. Welsh, and B. Earley. 2018. Comparison of single radial immunodiffusion and ELISA for the quantification of immunoglobulin $\mathrm{G}$ in bovine colostrum, milk and calf sera. J. Appl. Anim. Res. 46:758-765. https://doi.org/10.1080/09712119.2017.1394860.

Elsohaby, I., J. T. McClure, M. Cameron, L. C. Heider, and G. P. Keefe. 2016. Rapid assessment of bovine colostrum quality: How reliable are transmission infrared spectroscopy and digital and optical refractometers? J. Dairy Sci. 100:1427-1435. https://doi.org/ $10.3168 /$ jds.2016-11824.

Evans, J. D. 1996. Straightforward Statistics for the Behavioral Sciences. Brooks/Cole Publishing, Pacific Grove, CA.

Gelsinger, S. L., A. M. Smith, C. M. Jones, and A. J. Heinrichs. 2015. Technical note: Comparison of radial immunodiffusion and ELISA for quantification of bovine immunoglobulin $\mathrm{G}$ in colostrum and plasma. J. Dairy Sci. 98:4084-4089. https://doi.org/10.3168/jds .2014-8491

Gulliksen, S. M., K. I. Lie, L. Sølverød, and O. Østerås. 2008. Risk factors associated with colostrum quality in Norwegian dairy cows. J. Dairy Sci. 91:704-712. https://doi.org/10.3168/jds.2007-0450.

Holloway, N. M., J. W. Tyler, J. Lakritz, S. L. Carlson, and J. Holle. 2001. Serum immunoglobulin G concentrations in calves fed fresh and frozen colostrum. J. Am. Vet. Med. Assoc. 219:357-359. https: //doi.org/10.2460/javma.2001.219.357.

Hunter, A. G., J. K. Reneau, and J. B. Williams. 1977. Factors affecting IgG concentration in day-old lambs. J. Anim. Sci. 45:11461151. https://doi.org/10.2527/jas1977.4551146x.

Kessler, E. C., R. M. Bruckmaier, and J. J. Gross. 2019. Immunoglobulin G content and colostrum composition of different goat and sheep breeds in Switzerland and Germany. J. Dairy Sci. 102:55425549. https://doi.org/10.3168/jds.2018-16235.

Kruse, V. 1970. Absorption of immunoglobulin from colostrum in newborn calves. Anim. Prod. 12:627-638. https://doi.org/10.1017/ S0003356100029275.

Lin, L. I. 1989. A concordance correlation coefficient to evaluate reproducibility. Biometrics 45:255-268. https://doi.org/10.2307/ 2532051.

McGuire, T. C., and D. S. Adams. 1982. Failure of colostral immunoglobulin transfer to calves: Prevalence and diagnosis. Compend. Contin. Educ. Pract. Vet. 4:S35-S39.

Moreno-Indias, I., D. Sánchez-Macías, N. Castro, A. Morales-delaNuez, L. E. Hernández-Castellano, J. Capote, and A. Argüello. 2012. Chemical composition and immune status of dairy goat colostrum fractions during the first $10 \mathrm{~h}$ after partum. Small Rumin. Res. 103:220-224. https://doi.org/10.1016/j.smallrumres.2011.09.015.

Morrill, K. M., K. E. Robertson, M. M. Spring, A. L. Robinson, and H. D. Tyler. 2015. Validating a refractometer to evaluate immunoglobulin G concentration in Jersey colostrum and the effect of multiple freeze-thaw cycles on evaluating colostrum quality. J. Dairy Sci. 98:595-601. https://doi.org/10.3168/jds.2014-8730.

O'Brien, J. P., and D. M. Sherman. 1993. Serum immunoglobulin concentrations of newborn goat kids and subsequent kid survival through weaning. Small Rumin. Res. 11:71-77. https://doi.org/10 .1016/0921-4488(93)90119-3.

Oyeniyi, O. O., and A. G. Hunter. 1978. Colostral constituents including Immunoglobulins in the first three milkings postpartum. J. Dairy Sci. 61:44-48. https://doi.org/10.3168/jds.S0022 $-0302(78) 83549-8$.

Perkins, N. J., and E. F. Schisterman. 2006. The inconsistency of "optimal" cutpoints obtained using two criteria based on the receiver operating characteristic curve. Am. J. Epidemiol. 163:670-675. https://doi.org/10.1093/aje/kwj063.

Quigley, J. D., A. Lago, C. Chapman, P. Erickson, and J. Polo. 2013. Evaluation of the Brix refractometer to estimate immunoglobulin G concentration in bovine colostrum. J. Dairy Sci. 96:1148-1155. https://doi.org/10.3168/jds.2012-5823.
Reschke, C., E. Schelling, A. Michel, F. Remy-Wohlfender, and M. Meylan. 2017. Factors associated with colostrum quality and effects on serum gamma globulin concentrations of calves in Swiss dairy herds. J. Vet. Intern. Med. 31:1563-1571. https://doi.org/10 $.1111 /$ jvim. 14806 .

Romero, T., M. C. Beltrán, M. Rodríguez, A. M. De Olives, and M. P. Molina. 2013. Short communication: Goat colostrum quality: Litter size and lactation number effects. J. Dairy Sci. 96:7526-7531. https://doi.org/10.3168/jds.2013-6900.

Rudovsky, A., L. Locher, A. Zeyner, A. Sobiraj, and T. Wittek. 2008. Measurement of immunoglobulin concentration in goat colostrum. Small Rumin. Res. 74:265-269. https://doi.org/10.1016/j .smallrumres.2007.06.003.

Selim, S. A., B. P. Smith, J. S. Cullor, P. Blanchard, T. B. Farver, R. Hoffman, G. Dilling, L. Roden, and B. Wilgenburg. 1995. Serum immunoglobulins in calves: Their effects and two easy reliable means of measurement. Vet. Med. 90:387-404.

Silva-del-Río, N., D. Rolle, A. García-Muñoz, S. Rodríguez-Jiménez, A. Valldecabres, A. Lago, and P. Pandey. 2017. Colostrum immunoglobulin G concentration of multiparous Jersey cows at first and second milking is associated with parity, colostrum yield, and time of first milking, and can be estimated with Brix refractometry. J. Dairy Sci. 100:5774-5781. https://doi.org/10.3168/jds.2016-12394.

Stevenson, M. 2020. Package 'epiR' - Tools for the analysis of epidemiological data. https://fvas.unimelb.edu.au/research/groups/ veterinary-epidemiology-melbourne.

Torres-Rovira, L., J. L. Pesantez-Pacheco, F. Hernandez, L. ElviraPartida, M. L. Perez-Solana, J. V. Gonzalez-Martin, A. Gonzalez-Bulnes, and S. Astiz. 2017. Identification of factors affecting colostrum quality of dairy Lacaune ewes assessed with the Brix refractometer. J. Dairy Res. 84:440-443. https://doi.org/10.1017/ S002202991700070X.

Tyler, J. W., D. D. Hancock, J. G. Thorne, C. C. Gay, and J. M. Gay. 1999. Partitioning the mortality risk associated with inadequate passive transfer of colostral immunoglobulins in dairy calves. J. Vet. Intern. Med. 13:335-337. https://doi.org/10.1111/j.1939-1676 .1999.tb02191.x.

Virtala, A. M., Y. Grohn, G. Mechor, and H. Erb. 1999. The effect of maternally derived immunoglobulin $\mathrm{G}$ on the risk of respiratory disease in heifers during the first 3 months of life. Prev. Vet. Med. 39:25-37. https://doi.org/10.1016/S0167-5877(98)00140-8.

Weaver, D. M., J. W. Tyler, D. C. VanMetre, D. E. Hostetler, and G. M. Barrington. 2000. Passive transfer of colostral immunoglobulins in calves. J. Vet. Intern. Med. 14:569-577. https://doi.org/10 $.1111 /$ j.1939-1676.2000.tb02278.x.

Xavier, R., N. Turck, A. Hainard, N. Tiberti, F. Lisacek, M. Sanchez, and J.-C. Müller. 2011. pROC: An open-source package for R and $\mathrm{S}+$ to analyze and compare ROC curves. BMC Bioinformatics 12:77. https://doi.org/10.1186/1471-2105-12-77.

Yang, X. Y., J. P. Chen, and F. X. Zhang. 2009. Research on the chemical composition of Saanen goat colostrum. Int. J. Dairy Technol. 62:500-504. https://doi.org/10.1111/j.1471-0307.2009.00515.x.

Youden, W. J. 1950. Index for rating diagnostic tests. Cancer 3:32-35. https://doi.org/10.1002/1097-0142(1950)3:1<32::AIDCNCR2820030106>3.0.CO;2-3.

\section{ORCIDS}

G. Zobel ๑ https://orcid.org/0000-0002-9883-9503

R. Rodriguez-Sanchez $\mathbb{~}$ https://orcid.org/0000-0002-9672-0373

S. Y. Hea (1) https://orcid.org/0000-0003-3464-9804

A. Weatherall ๑ https://orcid.org/0000-0003-4896-4004 